Filol. linguíst. port., São Paulo, 15(2), p. 519-541, Jan./Jun. 2013.

DOI: http://dx.doi.org/10.11606/issn.2176-9419.v15i2p519-541.

\title{
Gradualismo do processo de gramaticalização e princípio da persistência: indícios de uma hierarquia de traços?
}

Gradualism of the process of grammaticalization and the principle of persistence: evidence of a hierarchy of features?

\author{
Sueli Maria Coelho \\ Universidade Federal de Minas Gerais, Brasil \\ suelimcoelho@gmail.com
}

Resumo: A partir da análise de casos prototípicos de gramaticalização que, estudados numa perspectiva diacrônica, atestam uma persistência de traços formais, este texto discute a tese de que os traços definidores das categorias gramaticais são marcados hierarquicamente no sistema linguístico. Dessa forma, assume-se que existem traços mais fortes que outros, fato que explicaria sua persistência até mesmo em estágios avançados do processo de gramaticalização, e se propõe uma hierarquia para tais traços em dois níveis, sendo um deles macro, tomando por parâmetro o estrato em que a mudança categorial se processa, e o outro micro, analisando-se os traços em cada estrato.

Palavras-chave: Traços formais. Traços semânticos. Hierarquia. Gramaticalização. Princípio da persistência.

\begin{abstract}
From the analysis of prototypical cases of grammaticalization that were studied in a diachronic perspective and that have attested a persistence of formal features, this text discusses the thesis that the features that define the grammatical categories are hierarchically marked in the linguistic system. This way, it is assumed that there are features stronger than others, which could explain their persistence even in advanced stages of the process of grammaticalization, and it is proposed a hierarchy for such features into two levels, a macro one, taking as a parameter
\end{abstract}


the stratum in which the categorical change takes place, and a micro one, for analyzing the features in each stratum.

Keywords: formal features, semantic features, hierarchy, grammaticalization, persistence principle.

\section{CONSIDERAÇÕES INICIAIS}

A despeito de o século XIX constituir, na história da Linguística, o marco para os estudos de cunho histórico-comparativo, tal perspectiva de abordagem dos fenômenos da língua não está ultrapassada e, ainda hoje, transcorridos dois séculos, mostra-se um recurso metodológico providencial para auxiliar no entendimento de alguns princípios que continuam a atuar não apenas no desencadeamento de fenômenos de mudança linguística, bem como em sua implementação. Dessa forma, o apelo a explicações diacrônicas e à comparação entre as diversas línguas, quer de mesma família, quer de famílias distintas, continua sendo um meio de que o pesquisador se vale para buscar descrever e interpretar processos e fenômenos que parecem se comportar de forma regular não só ao longo do tempo, como também na história das diversas línguas.

Mais especificamente no que toca ao processo de mudança linguística, a abordagem diacrônica assume um lugar privilegiado, especialmente em relação a determinados estratos linguísticos, nos quais as mudanças se processam de forma bem mais lenta, porque seus efeitos implicam alterações mais profundas e sensíveis, cujos reflexos podem alterar a estrutura do sistema, impondo-lhe um novo parâmetro. Entretanto, em qualquer dos níveis em que a mudança se processa, o gradualismo do processo é assumido, se não por todos, pelo menos pela grande maioria dos estudiosos, o que acaba por permitir que, no continuum linguístico, identifiquem-se resquícios de estágios cronologicamente anteriores. Em se tratando da gramaticalização ${ }^{1}$ de itens/construções, tais resquícios emergem, ainda que de forma latente, em dois dos princípios propostos por Hopper (1991) para aferir o grau de gramaticalização de uma forma: o princípio da persistência e o princípio da descategorização. Apoiado na tese da emergência da gramática, concebida como atribuição de novas funções

\footnotetext{
${ }^{1}$ Embora não seja consensual entre os pesquisadores o fato de a gramaticalização constituir um processo de mudança linguística, dado que suas etapas diferem da proposta laboviana, no sentido de não haver uma concorrência de formas nem, consequentemente, a substituição de uma forma pela outra, estamos assumindo que se trata de uma mudança linguística, em vista das alterações categoriais que dela advêm.
} 
a formas já existentes, Hopper (1991) considera possível identificar graus variados de gramaticalização nas formas do continuum linguístico e, para tanto, propõe cinco princípios que, conforme mencionado, visam a medir o grau de gramaticalização dessas formas. Dentre tais princípios, ater-nos-emos apenas aos dois anteriormente evocados por serem eles os que se relacionam de modo direto e estrito ao objeto de nossa atenção neste ensaio. O princípio da persistência prevê, segundo o autor referenciado, a possibilidade de alguns traços de significado, isto é, de resquícios da referenciação extralinguística da categoria lexical (forma-fonte) serem mantidos na forma gramaticalizada (forma-alvo), o que pode, segundo ele, vir a interferir nas restrições sintáticas da nova forma. Lopes (2010: 278) propõe estender esse princípio de Hopper (1991) para além dos traços semânticos, apoiada no argumento de que "os detalhes da história lexical do item' não se restringem aos valores semânticos, mas também às suas características formais." Segundo defende a autora,

a persistência de propriedades do item original na nova forma gramaticalizada é, por assim dizer, um dos aspectos mais preponderantes nesse processo de mudança por gramaticalização, uma vez que os traços identificados pelo princípio da persistência marcarão as particularidades da forma que se recategoriza. (Lopes, 2010: 278)

O segundo princípio de que nos ocuparemos, o da descategorização, remete, de acordo com Hopper (1991), à perda ou à neutralização, por parte da forma-fonte, de flexões morfológicas e de privilégios sintáticos, decorrentes do processo de abstração por que passa tal forma rumo à categoria gramatical. Lopes (2010: 279) acredita que ambos os princípios estejam imbricados, já que,

pelo gradualismo do processo, a decategorização pode evidenciar algumas persistências, uma vez que nem todas as propriedades lexicais são perdidas e muito menos são assumidas todas as características da nova categoria da qual passou a fazer parte a forma gramaticalizada.

Apoiada na análise de casos clássicos de gramaticalização, a autora conclui que "os itens lexicais ou construções, ao se tornarem mais gramaticais, perdem algumas das propriedades formais e semânticas do item-fonte, enquanto outras persistem na forma gramaticalizada." (Lopes, 2010: 306) Portanto, segundo defende essa pesquisadora, é possível, por meio de dados fornecidos pela diacronia, identificar, nas formas gramaticalizadas, resquícios também de traços 
formais ${ }^{2}$ responsáveis por explicar não apenas determinadas especificidades das formas, bem como por impor-lhes algumas restrições, conforme já defendia Hopper (1991) para os resquícios semânticos identificados em algumas formas.

A tese defendida e justificada por Lopes (2010) suscita outra questão, que será objeto de nossa especulação ao longo deste texto: a hierarquia de traços. Se, como defende a autora, há traços formais da forma-fonte que não se perdem nem se neutralizam com o avançar do processo de gramaticalização, parecenos plausível cogitar a respeito da provável existência de uma hierarquia entre os traços formais, isto é, parece-nos pertinente admitir que existam alguns traços que são mais fortes ${ }^{3}$ que outros e que, por isso, não se esvaem. Nossa hipótese advém da seguinte questão: sabendo-se que, ao longo do processo, algumas propriedades categoriais da forma-fonte se perdem ou se neutralizam enquanto outras não o fazem, o que determinaria a persistência de algumas propriedades/traços? Acreditamos que determinadas categorias gramaticais sejam mais fortemente marcadas que outras, fator que impede que suas propriedades, determinadas por seus traços formais, desapareçam durante um processo de mudança de forma lexical em forma gramatical ou mesmo de acentuação de gramaticalidade, no caso de formas já gramaticalizadas. Isso atestaria, a nosso ver, a existência de uma hierarquia de traços não no sentido de precedência de um sobre o outro, mas no sentido de gradualismo de intensidade da marcação das categorias gramaticais. Se nossa hipótese se mostrar adequada e, por isso, encontrar respaldo entre nossos pares, acreditamos que ela trará implicações não apenas para os estudos de cunho formal, bem como para os estudos da gramaticalização, sobretudo para a controversa questão da (im)possibilidade de haver desgramaticalização. Se, de fato, pudermos comprovar uma hierarquia de traços determinada pela existência de traços que frequentemente se mantêm até mesmo nos estágios mais avançados do processo de gramaticalização, certamente não será possível cogitar a respeito de um processo de desgramaticalização, o que contribuirá para atestar a unidirecionalidade do fenômeno, como já propuseram vários estudiosos do tema.

\footnotetext{
${ }^{2} \mathrm{O}$ que está sendo tratado sob a denominação de traços formais aqui são as propriedades gramaticais do item/construção que, ao se gramaticalizar, mantém algumas de suas antigas propriedades gramaticais, assim como pode manter algumas de suas propriedades semânticas.

${ }^{3} \mathrm{~A}$ noção de traços fortes e de traços fracos aqui proposta não corresponde àquela proposta por Chomsky (1995), pois os atributos fortes e fracos aqui empregados visam a traduzir tão somente um gradualismo de marcação do traço.
} 
Constitui, pois, nosso desafio ao longo deste texto buscar evidências em favor da conjetura da hierarquia de traços, bem como tentar identificar algum gradualismo nessa hierarquia, isto é, a partir da análise de resquícios de traços já identificados por pesquisadores de processos de gramaticalização, tanto do português quanto de outras línguas, precisar quais categorias mostram-se mais recorrentes, o que atestaria sua persistência e, consequentemente, sua marcação mais forte em relação às demais. Para alcançarmos os limites dos objetivos a que nos propomos, partiremos, como já anunciado, da análise de um conjunto de fenômenos de gramaticalização nos quais se identificam resquícios de traços formais, levantamento que será descrito na primeira seção deste texto. Na segunda seção, empenharemos esforços para identificar quais traços se mostram mais fortemente marcados no conjunto dos fenômenos analisados, os quais serão tomados como corpus de nossa análise. Por fim, na terceira seção, apresentaremos nossa proposta de hierarquia entre os traços, seguida de nossas considerações finais, que visam a convocar o leitor a nos auxiliar nesta investigação cujos primeiros passos estão aqui ensaiados.

\section{Persistência de traços formais: resquícios da descategorização}

Esta seção, que se destina a constituir uma espécie de corpus para a discussão da hipótese que ora se aventa, constrói-se a partir de uma coletânea de estudos nos quais os autores aqui citados atestam a existência de resquícios de traços formais em formas que passaram por um processo de mudança categorial. O recurso metodológico adotado é, pois, o de buscar ecos do passado no presente ou, para fazer jus à memória de Mattos e Silva, o de se predispor a "ouvir o inaudível" (2008). Por questões de natureza meramente didática, estabelecer-se-á um agrupamento entre os trabalhos consultados, apresentando-se primeiramente aqueles em que se identificam resquícios de traços morfológicos, seguidos daqueles em que tais resquícios centram-se nos domínios da sintaxe e, por fim, no plano textual.

Lopes (2010) inicia sua argumentação em favor da persistência de traços formais analisando um fenômeno panromânico de gramaticalização, que é a mudança categorial do nome mente em sufixo formador de advérbios de modo. Trata-se, sem dúvida, de um caso clássico e prototípico de gramaticalização, já que a forma nominal atinge o ápice do processo, convertendo-se em morfema derivacional. Recompondo a história pregressa da forma, a autora, apoiada em Câmara Júnior (1979), explica que "o nome 'mente' com o sentido de 'o modo, a maneira' era frequentemente utilizado como núcleo de um sintagma com valor adverbial sempre acompanhado/determinado por adjetivos em construções 
como: agir [cristã mente] = agir [de modo cristão]." (Lopes, 2010: 282) A partir de informações extraídas de Câmara Júnior (op. cit.) acerca da alta frequência desse mecanismo de expressão da circunstância de modo no latim vulgar, bem como da análise do papel preponderante que a frequência assume na implementação da mudança, segundo defendem Bybee (2003) e Company (2003), Lopes (2010) conclui que o fato de, no português, os advérbios em -mente formarem-se sempre a partir de uma base constituída por adjetivos femininos decorre de um resquício do traço de concordância estabelecido entre o nome mente, originalmente feminino no latim, e a forma adjetiva de função adverbial que se antepunha a ele.

Ainda na linha do resíduo da concordância, a autora discute a gramaticalização do pronome pessoal de terceira pessoa do português (ele), originário do demonstrativo latino ille. Segundo Lopes (op. cit.), o fato de o pronome de terceira pessoa ser o único do quadro pessoal a se flexionar em gênero e número ${ }^{4}$ explica-se pela manutenção de uma propriedade de sua antiga categoria demonstrativa, argumento também evocado para explicar seu caráter anafórico, em oposição às propriedades dêiticas próprias das duas primeiras pessoas.

O quadro pronominal do português parece pródigo em exemplos de manutenção de traços formais, os quais ainda se identificam na gramaticalização dos nomes gente e mercê como pronomes, respectivamente, de primeira e de segunda pessoa. Lopes e Rumeu (2007: 407) declaram que "durante a evolução diacrônica de a gente e você, não houve perda completa e imediata dos traços nominais e, muito menos, a adoção definitiva das propriedades pronominais." Segundo essas pesquisadoras, a forma gramaticalizada a gente herdou do substantivo gente não apenas o traço de concordância com a terceira pessoa, mas também sua propriedade de estabelecer uma referência indeterminadora e genérica ${ }^{5}$, o que lhe permitiu tornar-se uma variante da primeira pessoa do plural. No tocante à gramaticalização de você, também se constata a conservação do traço de pessoa, dado que,

\footnotetext{
${ }^{4} \mathrm{~A}$ autora esclarece que "os pronomes pessoais 'legítimos' não sofrem flexão de gênero/número (eu/nós, tu/vós), pois são itens lexicais diferentes, e não a variação de um mesmo item." (Lopes, 2010: 285)

${ }^{5}$ Para maiores detalhes acerca da manutenção da referência indeterminadora de $a$ gente, consultar Omena \& Braga (1996).
} 
ao ser utilizado como expressão de tratamento em vossa mercê, observa-se a conservação da pessoa formal $[\phi$ eu] típica do nome, com alteração da pessoa semântica, uma vez que passa com o possessivo vossa a ser utilizada como estratégia de referência à segunda pessoa do discurso, embora o verbo se mantenha na $3^{\text {a }}$ pessoa. (Lopes e Rumeu, 2007: 424)

Mesmo após você ser recategorizado, passando de forma de tratamento a pronome de segunda pessoa, é possível identificar uma marca de sua sincronia pretérita na manutenção da concordância com o nome mercê, o que faz o verbo flexionar-se na terceira pessoa do singular.

Essa neutralização de traços categorias pode ainda ser cotejada nos domínios da sintaxe. Retomando, mais uma vez, um caso extremo de cristalização de forma lexical em morfema flexional, Lopes (2010) discute a gramaticalização do morfema de futuro nas línguas românicas, interpretando a colocação mesoclítica que lhe é peculiar como um resquício da sua história. Originário do auxiliar latino habere (amare habēo $>$ amar hei $>$ amarei), o morfema -ei, marcador do futuro sintético português, traz ecos de seu percurso diacrônico, não apenas quando deixa entrever sinais de sua função volitiva originária no latim vulgar, por meio da qual focalizava, "do presente, a vontade de que uma ocorrência se desse" (Câmara Jr, 1979: 130), mas também na ordenação do clítico pronominal. Segundo Lopes (op. cit.),

no caso da formação desses novos futuros sintéticos em português, seja do presente, amarei, seja do pretérito, amaria, embora em desuso, tem-se como "regra prescritiva" o emprego do pronome oblíquo mesoclítico. Na realidade, a descrição gramatical prevê que as únicas formas verbais que admitem mesóclise são esses dois tempos verbais originados de antigas formas perifrásticas. A mesóclise (abolida no português falado e rara na escrita) poderia ser considerada um resquício do antigo futuro analítico constituído de infinitivo + habere. O pronome ocorre justamente entre o antigo infinitivo e o verbo auxiliar: encontrar-te-ei, pagá-lo-ia etc. (Lopes, 2010: 282)

Bybee (2010) também atesta casos de resíduos formais interferindo na ordenação de algumas construções verbais do inglês. De acordo com essa linguista, "porque as novas construções são estágios específicos de construções antigas, muitas de suas propriedades, como a disposição de constituintes, são 
determinadas pelas construções das quais elas se originam ${ }^{6}$." (p. 110, tradução nossa) Segundo a autora, a explicação para o fato de a partícula negativa not ocorrer preferencialmente após o primeiro auxiliar ou após o verbo copulativo explica-se por um resíduo diacrônico:

o elemento not formou-se no Inglês Médio a partir de uma partícula negativa $n \bar{a}$ ou $n \bar{o}$ mais um pronome indefinido wiht significando "alguém, algo", quando este pronome era o objeto do verbo. Sendo o objeto direto do verbo, num estágio em que VO era a ordem normal, a negativa sucedeu o verbo. De fato ela seguia todos os verbos, incluindo verbos principais finitos, mas tornou-se, mais tarde, restrita aos auxiliares seguintes e às cópulas ${ }^{7}$. (Bybee, 2010: 110, tradução nossa)

Esses resquícios formais são ainda responsáveis por determinar a ordem dos verbos constituintes de uma perífrase verbal. Para Bybee (op. cit.), o fato de, em línguas OV, o verbo auxiliar se pospor à forma principal, enquanto nas línguas VO ocorrer o contrário explica-se do seguinte modo:

Verbos auxiliares se desenvolvem a partir de verbos principais, os quais tomam outros verbos como complementos. Nas línguas OV tais complementos precedem o verbo finito (aquele que irá se tornar o auxiliar) enquanto nas línguas $\mathrm{VO}$ os complementos seguem o verbo finito. Desse modo a ordem V-AUX será característica de línguas OV enquanto a ordem oposta será característica de línguas $\mathrm{VO}^{8}$. (Bybee, 2010: 111, tradução nossa)

${ }^{6}$ Do original: "[...] because new constructions are specific instances of old constructions many of their properties, such as element ordering, are determined by the construction from which they arose." (Bybee, 2010: 110)

${ }^{7}$ Do original: [...] the element not derived in Middle English from a negative elemento $n \bar{a}$ or $n \bar{o}$ plus an indefinite pronoun wiht meaning 'someone, something' when the latter pronoun was the object of the verb. Being the direct object of the verb, at a stage when VO was the normal order, the negative followed the verb. It actually followed all verbs, including main finite verbs, but was later restricted to following auxiliaries and copulas [...]" (Bybee, 2010: 110)

${ }^{8}$ Do original: "Auxiliary verbs develop from main verbs themselves, main verbs that take other verbs as complements. In OV languages such complements precede the finite verb (the one that will become the auxiliary) while in VO languages the complements follow the finite verb. Thus the order V-AUX will be characteristic of OV languages while the opposite order will be characteristic of VO languages." (Bybee, 2010: 111) 
Essa marcação formal da ordem é tão arraigada que determina, segundo a autora em tela, até mesmo o tipo de morfema em que a forma gramaticalizada se recategoriza, caso ela atinja o estágio mais avançado do processo de gramaticalização. Assim, em se tornando afixos, tais auxiliares serão sufixos nas línguas OV e, prefixos, nas línguas VO.

Coelho (2006) também encontrou evidências de resquícios formais atuando em construções verbais do português brasileiro. Diferentemente dos trabalhos anteriormente mencionados, os resquícios formais identificados pela autora não se relacionam estritamente à ordem dos constituintes, mas à propriedade da forma gramaticalizada de selecionar argumentos, o que define a relação de subordinação que se estabelece no interior da perífrase. Segundo defende Coelho (op. cit.), ao se gramaticalizar, o verbo auxiliar mantém a propriedade de selecionar argumentos e, por isso, assume o papel de termo regente na construção. Assim, numa perífrase verbal, cabe a ele o papel de selecionar a forma nominal que com ele passa a coocorrer, o que se dá por meio de um princípio de subcategorização, isto é, o verbo auxiliar toma a forma nominal como seu complemento, respeitando, para tanto, critérios sintáticos e semânticos.

No plano das categorias que assumem uma função textual, há também registro de manutenção de traços funcionais de estágios linguísticos anteriores. Gonçalves et al. (2007), citando trabalhos de Paul (1886), explicam que as conjunções "derivam historicamente de advérbios conjuncionais ou de alguns usos de pronomes conjuncionais, itens que já serviam para ligar orações antes mesmo de se transformarem em conjunções." (Gonçalves et al., 2007: 92, grifos nossos) Na mesma linha, Lyons (1979), ao discutir a obscuridade que a separação das palavras em classes segundo os parâmetros da gramática tradicional impõe às suas relações diacrônicas, apresenta a origem comum do valor anafórico dos pronomes demonstrativos, dos artigos e dos pronomes pessoais de terceira pessoa. Ele lembra que os pronomes de terceira pessoa das línguas românicas, do inglês e do alemão, bem como o artigo definido dessas línguas têm sua origem nos pronomes demonstrativos, fato responsável por todas essas três classes carregarem o traço [+ definido], que lhes permite a referência anafórica e, consequentemente, o papel de elemento de coesão textual.

Atestada, a partir dos casos ilustrados nesta seção, a existência de resíduos de traços morfológicos, sintáticos e funcionais em estágios mais avançados de recategorização de formas, cumpre perseguir nosso objetivo, buscando identificar algum indício de hierarquia entre os traços formais cuja persistência foi aqui comprovada, o que será objeto de nosso exame na próxima seção. 


\section{Gradualismo de marcação: traços fortes e traços fracos}

Tomando os resíduos de traços descritos na seção precedente como fonte de dados, parece-nos que já estamos em condições de buscar uma sistematização para nossa proposta, a partir da análise do modo como se marcam formalmente as categorias gramaticais nas línguas. Antes, porém, conforme defende Lyons (1979), convém definir tecnicamente a expressão categoria gramatical, já que o termo categoria tem sido utilizado de modo polissêmico na teoria gramatical moderna. Tradicionalmente, conforme explica o linguista citado (Lyons, 1979: 285), o termo categoria é empregado para se referir "a certos traços associados às 'partes do discurso' nas línguas clássicas": pessoa, tempo, modo, número, gênero e caso, acepção que também estamos adotando neste trabalho. Tal termo, como grande parte da epistemologia do pensamento gramatical, tem uma base filosófica, mais especificamente radicada na teoria aristotélica. Lyons (1979: 286) explica que o termo

categoria deriva de uma palavra grega que também é traduzida como predicação, no sentido lógico ou filosófico de "atribuir propriedades" às coisas. Na filosofia aristotélica (e escolástica), as categorias eram as diferentes maneiras, ou modos, pelos quais se podia atribuir propriedades às coisas; e partia-se do princípio de que os diferentes modos de predicação representavam diferenças no mundo objetivo, diferentes modos de "ser".

Essas propriedades - "acidentes", na terminologia aristotélica - serviam para assinalar as diversas formas que as palavras assumiam de acordo não só com sua função sintática, mas também com o seu modo de significar. Dessa forma, "aquilo que tradicionalmente se denomina categorias gramaticais são, portanto, as categorias 'acidentais' da teoria gramatical e isso explica o termo mais antigo acidente (do latim accidentia), para o que agora chamamos 'variação flexional"'. (Lyons, 1979: 287-289) Por questões de conveniência terminológica, alguns autores, incluindo o próprio Lyons (op. cit.), adotam a terminologia categorias gramaticais primárias para se referir às partes do discurso, reservando a terminologia categorias gramaticais secundárias para se referir às categorias acidentais das quais estamos nos ocupando neste texto, o que, conforme mencionado, denota apenas um critério terminológico que não visa, de modo algum, a refletir qualquer tipo de hierarquia entre tais categorias, como pode sugerir o ordinal empregado nas referidas nomenclaturas.

Concebendo, portanto, as categorias gramaticais como traços que se associam às partes do discurso para expressar seus acidentes, parece-nos conveniente iniciar nossa reflexão a partir da análise de como se dá a marcação 
desses traços, já que acreditamos ser possível estabelecer algum tipo de relação entre essa marcação e o suposto gradualismo que estamos propondo. Conforme é sabido, há dois critérios básicos para a marcação dessas categorias, dos quais decorrem dois tipos de traços: (i) traços formais, aqueles cujo critério de marcação subordina-se à forma mais que ao sentido, determinado que é por fatores morfológicos e fonológicos, e (ii) traços semântico-discursivos, aqueles em que a marcação é tida como natural, dado que se pauta no sentido, sem levar em consideração questões ligadas à forma ${ }^{9}$. Em se tratando da marcação formal, Rooryck (1994) defende que os traços carregam determinados valores, que podem ser positivos, negativos ou ausentes, quando não especificados. $\mathrm{O}$ autor trabalha ainda com a ideia de subespecificação, da qual decorrem mais dois tipos de traços: (i) variáveis ( $\alpha$-traços), aqueles que não carregam em si o valor do traço, podendo ter o valor positivo ou negativo marcado sintaticamente, isto é, no contexto; é o caso, por exemplo, do lexema menin-, que é compatível tanto com o feminino quanto com o masculino, cabendo-lhe, por isso, a representação [ $\alpha$ feminino]. Já os (ii) traços não variáveis $(\phi$ traço) marcam, segundo a proposta do autor, simplesmente a ausência de um valor para o traço, o que os qualifica como neutros. Rooryck (op. cit.) defende que traços default são representados como [ $\phi$ traço], em virtude de sua representação genérica.

Nossa intuição é a de que os traços formais tendem a ser mais persistentes diacronicamente que os traços semânticos, pois as abstrações semânticas por que passa uma forma em seu percurso de mudança tendem a neutralizar a percepção de uma marcação natural, o que, a nosso ver, torna-a potencialmente mais susceptível à perda. Nosso raciocínio encontra eco no trabalho de Corbett (1991). Dedicando-se a um estudo exaustivo da categoria de gênero em diversas línguas, o autor constatou que o papel dos traços semânticos é, por vezes, bastante limitado para a marcação dessa categoria, especialmente em algumas línguas, dado que a visão de mundo do falante nativo é determinante para esse tipo de marcação. Como tal conhecimento falta a um observador externo, o critério semântico tende à ineficácia, o que impõe a adoção de recursos de natureza formal. Tais recursos também se mostraram preponderantes, segundo o autor, em um antigo idioma hamítico da Tanzânia, pois, nesse idioma, o gênero é identificado via história derivacional dos nomes, que se formam a partir de duas classes de verbos, sendo uma delas fonte de nomes masculinos e a outra, de nomes femininos. Outra evidência em favor de nossa ideia encontra-se na seguinte afirmação de Mark et al. (2007: 717, tradução nossa):

\footnotetext{
${ }^{9}$ Convém esclarecer que essa distinção entre os traços tem um caráter didático para fins de precisar o tipo de marcação, mas, provavelmente, há alguma inter-relação entre os dois tipos de traços, já que é possível haver na língua algum tipo de implicação entre traços semânticos e formais.
} 
Línguas ancestrais se cindem para formar línguas aparentadas que pouco se divergem, já que partilham traços lexicais, fonológicos e gramaticais que são substituídos por novas formas. No estudo das mudanças lexicais, a unidade de análise é o cognato. Cognatos são palavras de sentido similar com correspondência sistemática de sons indicando que eles se relacionam por linhagem comum ${ }^{10}$.

A despeito de o traço semântico ser evocado pelos autores para atestar a origem comum de itens lexicais, o traço preponderante na identificação do parentesco é o formal, pois a similaridade semântica é identificada, conforme mencionado pelos autores, por fatores de natureza fonológica; gramatical, portanto.

Retomando os dados referentes à persistência de traços morfológicos e apresentados na primeira seção, chamam-nos a atenção os resquícios diacrônicos de concordância, que se manifestam tanto na manutenção dos traços de gênero, quanto de pessoa e de número. Dentre esses, o traço de gênero parece-nos ser o mais fortemente marcado, porque se mostrou, na nossa compreensão, o mais persistente por duas razões principais: (i) manifesta-se no estágio mais avançado do processo de gramaticalização, quando a forma livre já se recategorizou em forma presa e (ii) impõe marcas de flexão a uma classe prototipicamente invariável, a dos advérbios, conforme demonstrou o trabalho de Lopes (2010). À semelhança do que se deu com o português, quando da passagem do nome mente a sufixo, Corbett (1991) registra a presença de concordância de gênero em advérbios não só do italiano, como também de algumas línguas do Ocidente, o que mostra certa produtividade desse tipo de resquício formal. Ampliando a lente de análise para além dos nossos dados e, recorrendo ao princípio metodológico adotado pelos linguistas comparativistas do séc. XIX, encontramos outras evidências em favor de que o gênero é, como estamos propondo, um traço fortemente marcado: Corbett (1991) identificou marcas de gênero, em verbos do russo ${ }^{11}$ e de algumas línguas

${ }^{10}$ Do original: "Ancestral languages split to form daughter languages that slowly diverge as shared lexical, phonological and grammatical features are replaced by novel form. In the study of lexical change, the unity of analysis is the cognate. Cognates are words of similar meaning with systematic sound correspondence indicating that they are related by common ancestry." (Mark, 2007: 717)

${ }^{11}$ Tais marcas não foram identificadas em formas de particípio, como ocorre no português, mas em formas principais, como ilustram estes exemplos do autor: "žurnal ležal- $\phi$ na stole (magazine lay-MASC on table); kniga ležal-a na stole (book lay-FEM on table); pis'mo ležal-o na stole (letter lay-NEUT on table)" (Corbett, 1991: 110) 
ergativas examinadas por ele, além de alguns indícios, em um dialeto flamenco rural, de que até mesmo complementizadores podem carregar concordância de gênero.

A despeito das evidências apresentadas, que atestam uma marcação forte para o traço de gênero, principalmente por sua manifestação em classes prototipicamente não marcadas quanto a essa categoria, não podemos nos olvidar de que, no sistema linguístico, pode haver uma imbricação entre categorias, de modo que uma venha a neutralizar a ocorrência de outra, suscitando a hipótese de um possível enfraquecimento de uma categoria na interação com outra(s). Buscando testar essa hipótese, encontramos alguns dados que a validam: a categoria de tempo, em russo, limita as possibilidades de concordância de gênero. Conforme demonstrado anteriormente, nessa língua, os verbos concordam em gênero com o sujeito, mas tal concordância se restringe, segundo Corbett (1991), ao passado e ao condicional; nos demais tempos verbais, a concordância se dá apenas com os traços de pessoa e de número. A categoria de pessoa, por seu turno, também pode interferir na concordância de gênero. Corbett (op. cit.), analisando a língua croata, encontrou casos em que a terceira pessoa do plural não é afetada pelo gênero do sujeito, como as demais pessoas o são. O mesmo se dá em relação à categoria de número que é, do ponto de vista da frequência, a que mais interage com a de gênero, fato que levou Greenberg (1963) a declarar que a presença de concordância de gênero no verbo em uma dada língua implica também a concordância de número. Em russo, a concordância de gênero se restringe ao singular, enquanto em algumas línguas tal restrição se dá em relação ao plural. Entretanto, segundo nosso entendimento, esses contraexemplos não desabonam a marcação forte que estamos atribuindo ao traço de gênero, dado que comprovam apenas uma restrição dessa categoria na interação com as demais. Há de se considerar, a nosso ver, que, embora neutralizada por determinados tempos, pessoas e números, a categoria de gênero não se extingue em face dessa interação, dado que ainda se manifesta nos demais tempos, pessoas e número aos quais a neutralização não se aplica, mantendo-se até mesmo em estágios avançados de mudança por gramaticalização, como ilustram nossos dados. Ademais, acreditamos que o fato de a categoria de gênero ser inerente aos substantivos, tanto nas línguas indo-europeias quanto nas línguas bantas, contribui para que ela seja mais fortemente marcada que as demais, que normalmente só se manifestam distribucionalmente.

Nossos dados mostraram também uma persistência formal das categorias de pessoa e de número, o que nos obriga a analisá-las tendo em vista a hierarquia que estamos propondo, isto é, cabe-nos justificar por que estamos propondo que os traços de pessoa e de número são menos fortemente marcados que o traço de gênero, além de tentar estabelecer um possível gradualismo entre pessoa e 
número. Começamos nossa análise dessas categorias defendendo que o traço de número é mais fortemente marcado que o traço de pessoa ${ }^{12}$. Nosso primeiro argumento está em consonância com o que apresentamos para o gênero, ou seja, apoia-se no fato de a categoria de pessoa, ao contrário da categoria de número, não possuir uma marcação gramatical, mas semântico-discursiva, já que ela é uma categoria dêitica - ancorada, portanto, na enunciação - que se define pela noção de papel. Nossa interpretação encontra respaldo na hierarquia de concordância proposta por Corbett (1991): atributivo < predicado < pronome relativo $<$ pronome pessoal. Segundo o autor, "quanto mais nos movermos para a direita na hierarquia, a probabilidade de concordância semântica aumentará [... $]^{13 "}$ (Corbett, 1991: 226, tradução nossa). A classe dos pronomes pessoais é, na hierarquia proposta pelo autor, a que mais apresenta concordância semântica, em oposição à classe dos atributivos, na qual a concordância se dá, prioritariamente, por critérios formais. Segundo Corbett (1991), a marcação semântica na classe dos pronomes pessoais é ainda favorecida quantitativamente pelo caso: "a probabilidade de concordância semântica no nominativo será tão ou mais alta que a probabilidade de concordância semântica nos casos oblíquos $^{14}$." (Corbett, 1991: 238, tradução nossa) Considerando-se que os resquícios da concordância de pessoa identificados em nossos dados reduzem-se ao quadro dos pronomes nominativos, encontramos aí mais um argumento em favor da marcação semântica na categoria de pessoa, fato que passaremos a testar contra nosso corpus.

A análise de Lopes (2010) atesta que o pronome nominativo de terceira pessoa carrega os traços de gênero e de número de sua antiga categoria de demonstrativo da qual herda também a função anafórica. Segundo Corbett (1991), em se tratando de gênero, os anafóricos não favorecem tanto a marcação semântica como os dêiticos. Isso porque, anaforicamente, eles podem referir-se

\footnotetext{
${ }^{12}$ Não nos passou despercebido o fato de tal proposta soar, num primeiro momento, contra intuitiva, principalmente se tomarmos como parâmetro o paradigma de concordância verbal do Português Brasileiro, que mantém o traço de pessoa, mas neutraliza o traço de número. Trata-se, contudo, de um fato sincrônico, que não se mantém diacronicamente. Ademais, conforme será argumentado, o traço de pessoa é mantido justamente por questões de natureza semântico-discursiva, para suprir o apagamento de um traço formal.

${ }^{13}$ Do original: "As we move rightwards along the hierarchy, the likelihood of semantic agreement will increase [...]" (Corbett, 1991: 226)

${ }^{14}$ Do original: "[...] the likelihood of semantic agreement in the nominative will be as high as or higher than the likelihood of semantic agreement in the oblique cases." (Corbett, 1991: 238)
} 
tanto a nomes femininos quanto a masculinos, o que os configura, segundo a proposta de traços de Rooryck (1994), como subespecificados para gênero, o que também se aplica para o número. Contudo, no que tange à categoria de pessoa, nas línguas românicas, a terceira pessoa é considerada "pessoa default", porque subespecifica o traço neutro $[\phi$ eu], o que lhe permite combinar-se com verbos que, em geral, levam desinência $\phi$. Essa subespecificação de traço neutro, a nosso ver, pode também indicar que a categoria de pessoa é menos marcada que as categorias de gênero e de número, que subespecificam, respectivamente, os traços variáveis [ $\alpha$ feminino] e [ $\alpha$ plural]. Resquícios do traço de pessoa foram ainda identificados por Lopes e Rumeu (2007) e retomados por Lopes (2010) para os pronomes você e a gente. As autoras ora referidas defendem que, em virtude da não correspondência obrigatória entre forma e sentido na língua, é imprescindível considerar, na análise, a coexistência de traços semânticos e formais atuando em uma mesma forma. Assim, o pronome você mantém, de acordo com a análise feita por elas, a concordância com a pessoa formal tributária do nome mercê, mas é interpretado semanticamente como pronome de segunda pessoa. Semelhante análise se aplica ao caso da mudança de gente para a gente, que manteve a interpretação semântica pluralizada como resquício da propriedade indeterminadora e genérica do nome gente, embora formalmente se conjugue no singular. O fato de a pessoa semântica prevalecer na recategorização das formas nominais em pronomes pessoais de primeira e de segunda pessoa vai ao encontro da afirmação de Corbett (1991) de que os dêiticos favorecem a concordância semântica. Por outro lado, não nos passa despercebido o fato de a concordância obedecer a princípios formais ditados pela categoria de número, mantendo o traço $[+$ singular $]$ dos antigos nomes. Segundo nosso entendimento, esses dados atestam não apenas uma marcação mais forte do traço de número sobre o de pessoa, como estamos propondo, bem como nos leva a cogitar acerca de uma possível influência da forma-fonte na manutenção dos traços formais de um continuum linguístico. Nesse caso, teríamos a coexistência de duas forças atuando conjuntamente no fenômeno, que seriam, respectivamente, a marcação formal do traço e a categoria da forma-fonte, o que também nos parece articulado com a hierarquia proposta por Corbett (1991), segundo a qual se associa probabilidade de marcação formal ou semântica de traços à categoria da forma. Nesse sentido estrito, entendemos ser possível perceber uma relação com a proposta de Chomsky (1995), segundo a qual os traços intrínsecos são especificados no léxico.

Cumprida a etapa da análise dos resquícios morfológicos, passemos à análise da persistência dos traços sintáticos que, no caso dos nossos dados, referem-se à ordem dos constituintes e à propriedade de subcategorização de argumentos pelo predicador verbal. Embora tenham sido apresentados como dois tipos de persistência de traços, acreditamos que se trata de um fenômeno imbricado, já 
que tanto a ordem dos constituintes quanto a subcategorização dizem respeito à hierarquia estrutural da oração. Assim, pautando-nos pelo mesmo parâmetro que propusemos para a análise dos traços morfológicos, entendemos que os traços sintáticos são traços fortemente marcados, não só por se manifestarem até mesmo em estágios de recategorização de forma livre em forma presa, como observado para o morfema -mente, mas também, e principalmente, porque são traços estritamente formais. Além disso, se considerarmos a possibilidade proposta no parágrafo anterior de que as categorias das formasfontes também influenciam no grau de marcação do traço e, consequentemente, em sua persistência ao longo do percurso de mudança, veremos que traços sintáticos são, de fato, traços fortes. Segundo a hierarquia proposta por Corbett (1991), os atributivos e os predicados são as categorias que mais atualizam traços formais. No caso da subcategorização sintática de argumentos, sabese, conforme Raposo (1992: 278), que "embora todas as categorias lexicais possam funcionar como predicadores, algumas delas têm, no entanto, uma 'predisposição' intrínseca para desempenhar esse papel: é o caso dos verbos e dos adjectivos, os predicadores por excelência." Ambos os predicadores mencionados por Raposo (op. cit.) estão descritos na escala de Corbett (op. cit.) como categorias marcadas prioritariamente por traços formais, o que constitui, segundo nossa proposta, um pré-requisito para ser um traço fortemente marcado.

Fixando o olhar em nossos dados, vemos que a possibilidade de mesóclise é interpretada como um resquício da antiga posição ocupada pelo auxiliar que se cristalizou em forma presa para marcação do futuro sintético. Essa interpretação de Lopes (2010) autoriza-nos a tratar as formas do futuro sintético como constituintes descontínuos facultativos que permitem a inserção do clítico pronominal na mesma posição em que se encontrava a forma auxiliar que lhe deu origem. É como se, ao se recategorizar em morfema de futuro, aglutinando-se ao verbo principal, o auxiliar tivesse deixado na estrutura um vestígio de sua antiga posição a qual pode vir a ser ocupada por uma forma clítica, que está, no continuum da gramaticalização, num estágio anterior ao da forma presa e, portanto, no mesmo estágio em que esse auxiliar se encontrava quando ocupava aquela posição na estrutura e se moveu para se aglutinar à forma verbal e se tornar um afixo. Fato semelhante parece ocorrer em relação aos dados descritos por Bybee (2010). Conforme apresentado, tanto a partícula de negação do inglês quanto os verbos auxiliares das tipologias linguísticas descritas pela autora ocupam, na estrutura superficial das sentenças, o mesmo lugar anteriormente ocupado pelas formas-fonte que os originaram, ou seja, os traços parecem definir os lugares. No caso da partícula negativa, esta sucede o verbo, ocupando, assim, o lugar anteriormente ocupado pelo complemento desse verbo, forma que lhe deu origem a partir da aglutinação entre antigas 
partículas negativas e um pronome definido subcategorizado pelo verbo. Sabese que a posição de complemento é, na estrutura sintática das línguas, uma posição obrigatória, já que o complemento é exigido pelo predicador verbal. Quando a categoria pronominal que ocupava tal posição passou por um processo de recategorização, transformando-se numa partícula negativa, tal partícula tende a ocupar esse lugar, que já estava definido na estrutura argumental do constituinte. Parece-nos, então, que a sintaxe aloca o item na estrutura segundo o seu traço forte mais antigo e a semântica o interpreta de acordo com o novo traço, aquele que define sua nova categoria. No caso dos auxiliares, sua anteposição ou posposição ao verbo principal da construção está também subordinada à posição do complemento que lhe originou, pois o auxiliar se conserva na estrutura no mesmo lugar ocupado pelo verbo finito que foi sua forma-fonte. Se compararmos o comportamento desses auxiliares com os morfemas em que eles se cristalizam, ao atingirem o grau máximo de gramaticalização, veremos que existe uma regularidade no sistema, no sentido de que a forma presa originária do auxiliar comporta-se da mesma forma que ele, refletindo a ordem sintática na estrutura morfológica. O fenômeno de manutenção de traço relatado por Coelho (2006) também envolve a subcategorização que, conforme se sabe, é uma propriedade lexical. Segundo nossa análise, esse é mais um indício de que há uma correlação entre as categorias da forma-fonte e o tipo de marcação de traços, conforme sugere a hierarquia proposta por Corbett (1991) e, consequentemente, entre elas e o grau de persistência do traço no percurso diacrônico de mudança. Conforme identificado por Coelho (2006), mesmo gramaticalizada em auxiliar, essa forma verbal não perde sua antiga propriedade de subcategorizar argumento interno, o que faz com que a forma principal seja tomada como seu complemento numa construção verbal. Tal como analisado para o caso da ordem dos auxiliares descrita por Bybee (2010), entendemos que essa propriedade não se perde não só porque integra a estrutura argumental do verbo, bem como porque faz parte da competência linguística do falante, isto é, tal marcação estrutural foi adquirida juntamente com a língua e, portanto, está bastante arraigada na gramática internalizada do falante, o que a torna praticamente impossível de ser extinta. Ademais, uma perda de traço no nível sintático acarretaria uma mudança de propriedades lexicais do item relacionada à seleção de argumentos, o que configuraria uma mudança profunda, já que afetaria a estrutura do sistema. Como se sabe, tais mudanças são passíveis de acontecer, mas se dão de forma bem mais lenta e gradual que aquelas que afetam outros estratos da língua.

Por fim, resta-nos comentar acerca dos resquícios funcionais identificados em nossos dados, isto é, aqueles resquícios em que a forma gramaticalizada carrega vestígios da antiga função desempenhada pela forma-fonte. Nossos dados 
ilustram dois casos, ambos relacionados à função textual, isto é, à articulação e à coesão do texto. Gonçalves et al. (2007) tratam da origem das conjunções a partir de advérbios e pronomes conjuncionais, que já desempenhavam a função de ligar orações, e Lyons (1979) trata da origem comum dos artigos definidos e dos pronomes de terceira pessoa, ambos oriundos da classe dos demonstrativos. $\mathrm{O}$ vestígio da função textual dos pronomes de terceira pessoa também foi mencionado por Lopes (2010) e discutido por nós, quando tratamos do resquício de pessoa, mas será aqui indiretamente abordado porque vamos nos ater às classes, conforme os autores as descreveram. Em nosso entendimento, o traço funcional manifesto nos artigos definidos e nos pronomes de terceira pessoa é mais fortemente marcado que aquele que se manifesta na classe das conjunções, pois, enquanto neste caso não é possível identificar um traço formal que defina a função, em se tratando dos demonstrativos, tem-se o traço da definitude, que carrega, segundo proposta de Rooryck (1994), o valor positivo, sendo, por isso, marcado formalmente como [ + definido]. Assim, nos termos de nossa proposta hierárquica, esse traço seria mais fortemente marcado que aquele manifesto nas conjunções. Além disso, se considerarmos a hierarquia de concordância proposta por Corbett (1991), veremos que os pronomes relativos, uma das categorias das quais se originam as conjunções, ocupam um lugar mais à direita da escala, o que indica maior propensão para atualizar marcação semântica e, consequentemente, segundo nossa proposta, maior possibilidade de atualização de traços menos fortemente marcados.

\section{Em busca do delineamento de uma hierarquia de traços}

Conforme critério exposto na seção precedente, estamos partindo do pressuposto de que os traços responsáveis por demarcar as categorias gramaticais são hierarquicamente marcados no sistema, o que explica o fato de, ao longo de um processo de mudança categorial de uma forma, determinados traços se esvaírem mais facilmente que outros. Tal hierarquia, segundo estamos propondo, relaciona-se a uma gradação na marcação do traço, o que decorre não só do tipo dessa marcação, mas também da categoria lexical da forma-fonte. Assim, conforme argumentamos, quando da análise dos resquícios de traços descritos na primeira seção, entendemos que traços cuja marcação é pautada em critérios fonológicos e gramaticais são mais fortemente marcados que traços cuja marcação decorre de fatores semântico-discusivos. Ademais, estamos propensos a acreditar que, tal como a categoria lexical da forma-fonte, o estrato linguístico a que o traço se vincula também interfere nesse gradualismo. Assim, entendemos ser possível propor dois tipos de hierarquia, sendo um deles manifesto no nível macro, considerando-se, nesse caso, os estratos linguísticos 
em que se processa a mudança, e outro, no nível micro, considerando-se os traços atualizados em cada estrato, conforme o princípio de marcação.

Atendo-nos primeiramente ao nível macro, acreditamos que, no caso de nossos dados, é possível propor a seguinte hierarquia, na qual o traço à esquerda é mais fortemente marcado que o traço à direita: traço sintático $>$ traço morfológico $>$ traço semântico $>$ traço funcional. Segundo nossa interpretação dos dados, os traços sintáticos, além de estritamente formais, tendem a ser mais persistente porque se fixam na gramática internalizada do falante, o que, a nosso ver, contribui para que, mesmo num processo de recategorização, determinadas relações hierárquicas e princípios de ordenação sejam mantidos, sob pena de se alterarem sensivelmente as propriedades do sistema internalizado. Em seguida, vêm os traços morfológicos cuja marcação se faz tanto por recursos formais quanto semânticos. A despeito de tais traços apresentarem também padrões definidos na gramática internalizada, as mudanças no nível da morfologia são, normalmente, mais frequentes e naturais que no nível da estrutura sintática, o que nos leva a propor que eles se posicionem, na escala, após os traços sintáticos. Os traços semânticos ocupam, em nossa escala, o limiar entre traços fortes e fracos. Isso porque, conforme argumentamos, acreditamos que o processo metafórico que envolve a mudança linguística corrobora para facilitar a dispersão de traços semânticos, embora a intuição do falante seja importante na identificação da categoria de gênero que, por ser inerente ao substantivo, é fortemente marcada. Por fim, aparecem os traços funcionais que, apesar de exibirem resquícios de marcação formal, são determinados mais por propriedades de natureza discursiva, o que nos parece torná-los mais flutuantes à interferência do falante.

No tocante ao nível micro, conforme análise desenvolvida na seção dois, acreditamos ser possível reconhecer uma hierarquia entre as categorias que se manifestam no estrato morfológico. Tal como proposto para a hierarquia no nível macro, também aqui o traço que se posiciona à esquerda é o mais fortemente marcado e, consequentemente, o que se posiciona à direita é aquele cuja marcação é mais fraca, o que o torna potencialmente menos susceptível à persistência no continuum linguístico. Segundo nossa análise, no estrato morfológico, teríamos a seguinte hierarquia: traço de gênero > traço de número > traço de pessoa. Os dois primeiros traços são formalmente marcados, enquanto o terceiro recebe uma marcação semântico-discursiva em decorrência de sua natureza dêitica. Assim, segundo o critério do tipo de marcação, o traço de pessoa é menos fortemente marcado que os demais. Em relação aos dois traços que apresentam marcação formal, o traço de gênero mostrou-se mais fortemente marcado que o traço de número por impingir a concordância até mesmo em categorias lexicais invariáveis quanto a essa 
categoria, como advérbios, verbos e complementizadores, e também por ser inerente ao substantivo, enquanto o número manifesta-se distribucionalmente.

No estrato sintático, conforme já mencionado para o nível macro, todos os traços são fortemente marcados e, no caso dos nossos dados, parecem relacionarse a um mesmo fenômeno, que é a organização hierárquica da sentença. Em decorrência dessa organização, determinadas posições são preservadas no sistema, o que determina a manutenção da ordem dos constituintes, mesmo em estágios mais avançados de recategorização de formas. Agregada à manutenção da ordem, a propriedade de subcategorização também se mostrou um traço fortemente marcado e, consequentemente, persistente, atuando nas relações de regência que se instauram no interior das construções verbais.

No estrato textual, nossos dados acusam uma gradação entre as funções preservadas dos demonstrativos pelos artigos definidos e pelos pronomes de terceira pessoa e aquela preservada dos advérbios pelas conjunções. Numa correlação entre o tipo de marcação de traço e a categoria lexical da forma, acreditamos que o traço [+ definido] herdado da classe dos demonstrativos pelos artigos e pelos pronomes de terceira pessoa os posiciona numa escala hierárquica superior à das conjunções, cujo critério de marcação é semântico discursivo. Assim, num percurso diacrônico, a propriedade de expressar a definitude tende a ser mais persistente que a função de estabelecer coesão entre os elementos de uma sentença, o que determina a propensão que a categoria dos itens relacionais apresenta para marcação semântica, conforme proposta de Corbett (1991).

\section{Considerações finais}

O entendimento de que a mudança categorial resultante da gramaticalização de itens/construções envolve perda de traços é tão consensual entre os vários estudiosos do tema que algumas definições do fenômeno apoiam-se nesse princípio, conforme esta, proposta por Clements (2012): "gramaticalização = estágio A (item com + traços) > estágio B (item com - traços)." Tal perda de traços manifesta-se não apenas no plano semântico, em decorrência do processo metafórico de abstração da forma que se desliza do léxico para a gramática ou de um estágio menos gramatical para um mais gramatical, como também no plano da gramática, quando ocorre, segundo prevê o princípio da descategorização proposto por Hopper (1991), perda de propriedades gramaticais da forma-fonte relacionada à sua categoria lexical. Entretanto, a despeito da comprovada perda de traços da forma-fonte ao longo de seu percurso de mudança categorial, estudos mais recentes têm demonstrado que, além dos traços semânticos, alguns traços gramaticais também são mantidos 
no continuum linguístico da forma, podendo ser recuperados a partir de uma perspectiva diacrônica de estudo da mudança. Esse fato motivou-nos a empreender a reflexão aqui apresentada, a partir da hipótese de que há uma hierarquia entre os traços, especialmente entre aqueles cuja função é assinalar as categorias gramaticais. Tal hierarquia, segundo propusemos, decorre de um gradualismo na marcação do traço, isto é, alguns traços são mais fortemente marcados que outros, o que explicaria a persistência de uns e o desaparecimento de outros ao longo do processo de mudança. Dessa forma, constituiu objetivo deste ensaio verificar a autenticidade da hipótese aventada, bem como tentar precisar tal hierarquia, caso ela fosse identificada.

A partir da análise de um conjunto de fenômenos de gramaticalização nos quais se atestam resquícios de traços morfológicos, sintáticos e funcionais mesmo em estágios bastante avançados do processo, chegamos às seguintes generalizações: (i) há uma hierarquia entre os traços a qual se subordina não somente ao modo como tais traços são marcados, como também à categoria lexical da forma-fonte e ao estrato linguístico no qual se processa a mudança categorial; (ii) traços formalmente marcados, isto é, aqueles assinalados por meio de recursos fonológicos e gramaticais, são mais fortemente marcados que aqueles cuja marcação se dá mediante recursos semântico-discursivos e, assim sendo, traços formais tendem a ser mais persistentes diacronicamente que traços semântico-discursivos; (iii) existem categorias lexicais que favorecem a marcação de traços formais e categorias nas quais essa marcação tende a ser semântica, variável interveniente no gradualismo desses traços; (iv) uma hierarquização no nível macro, segundo o estrato linguístico no qual a mudança se processa, compreende os seguintes níveis dispostos de forma decrescente: traço sintático $>$ traço morfológico $>$ traço semântico $>$ traço funcional; (v) num nível micro, considerando-se apenas os traços do estrato morfológico, tem-se a seguinte escala hierárquica, também organizada decrescentemente: traço de gênero $>$ traço de número $>$ traço de pessoa; (vi) os traços sintáticos são todos traços fortemente marcados e, dessa forma, tendem a ser mais persistentes, especialmente no tocante à ordenação dos constituintes; (vii) os traços funcionais ou textuais, por sua natureza pragmático-discursiva, tendem a ser mais flutuantes e, consequentemente, mais propensos à dispersão num continuum de mudança da forma.

Conforme registro em nossas considerações iniciais, nossa pretensão foi iniciar uma reflexão acerca de uma questão teórica cujos resultados refletem tanto nos estudos de cunho formal, quanto nos trabalhos sobre gramaticalização. Estamos conscientes de que as generalizações aqui apresentadas são apenas uma alavanca para pesquisas futuras, pois, endossando o pensamento de Corbett (1999: 143), acreditamos que "há um trabalho frutífero a ser feito nessa 
área, investigando outros grupos linguísticos ${ }^{15}$ ", com o objetivo de verificar a regularidade da manutenção dos traços formais e também de confirmar a hierarquia por nós esboçada, tarefa para qual convocamos você, leitor, a nos auxiliar.

\section{Referências}

BYBEE, J. Mechanisms of change in grammaticization: the role of frequency. In.: JOSEPH, B e JANDA, R. D. (orgs.) The handbook of historical linguistic. Oxford: Blackwell, 2003.

BYBEE, J. Language, usage and cognition. New York: Cambridge University Press, 2010.

CÂMARA JÚNIOR, J. M. História e estrutura da língua portuguesa. Rio de Janeiro: Padrão, 1979.

CLEMENTS, J. C. Congresso Internacional de Linguística Histórica, II, 2012, São Paulo. The development of key features in the Romance-Languages Sprachraum: an evolutionary approach. [Minicurso]. São Paulo: Universidade de São Paulo, 2012.

CHOMSKY, N. The minimalist program. USA: Cambrigde, MIT Press, 1995.

COELHO, S. M. (2006). Estudo diacrônico do processo de expansão gramatical e lexical dos itens TER, HAVER, SER, ESTAR e IR na Lingua Portuguesa. 2006. (Tese de Doutorado em Estudos Linguísticos) Belo Horizonte: Faculdade de Letras da Universidade Federal de Minas Gerais.

COMPANY COMPANY, C. ?Qué es um cambio linguístico? In.: SOLER, M. A. e AIROLDI, F. C. (coord.). Cambio linguístico y normatividad. México: Universidade Nacional Autônoma de México, 2003.

CORBETT, G. Gender: Cambrigde Textboobks in Linguistics. New York: Cambridge University Press, 1991.

GONÇALVES, S. C. L; LIMA-HERNANDES, M. C.; CASSEB-GALVÃO, V. C. (orgs.) Introdução à gramaticalização: princípios teóricos e aplicação. São Paulo: Parábola Editorial, 2007.

\footnotetext{
${ }^{15}$ Do original: "There is fruitful work to be done in this area, investigating other language groups [...]" (Corbett, 1991: 143)
} 
GREENBERG, J. H. Some universals of grammar with particular reference to the order of meaningful elements. In.: GREENGERG, J. H. (org.) Universal of language. Cambrigde, MA: MIT Press, 1966, P. 73-113.

HOPPER, P. J. On some principles of grammaticalization. In.: TRAUGOTT, E. C. e HEINE, B. (orgs.) Approaches to grammaticalization. vol. 1. Filadélfia: John Benjamins, 1991.

LOPES, Célia R. dos S. A persistência e a decategorização nos processos de gramaticalização. In.: VITRAL, L.; COELHO, S. M. (orgs.) Estudos de processos de gramaticalização em português: metodologias e aplicações. Campinas, SP: Mercado de Letras, 2010, p. 275-314.

LOPES, C. R. dos S.; RUMEU, M. C. de B. O quadro de pronomes pessoais do português: as mudanças na especificação dos traços intrínsecos. In.: Descrição, história e aquisição do português brasileiro. 1. ed. São Paulo/Campinas: FAPESP/Pontes Editores, 2007, v. 1, p. 419-436.

LYONS, J. Introdução à linguística teórica. São Paulo: C.E.N., 1979.

MARK, P.; ATKINSON, Q.; MEADE, A. Frequency of word- use predicts rates of lexical evolution throughout Indo-European history. In.: Nature. vol. 449. 11 out. 2007. p. 717-720.

MATTOS E SILVA, R. V. Caminhos da linguística histórica: "ouvir o inaudível". São Paulo: Parábola Editorial, 2008.

OMENA, N. P.; BRAGA, M. L. A gente está se gramaticalizando? In.: MACEDO, A. T.; RONCARATI, C.; MOLLICA, M. C. (orgs.) Variação e discurso. Rio de Janeiro: Tempo Brasileiro, 1996, p. 75-83.

RAPOSO, E. P. Teoria da gramática: a faculdade da linguagem. Lisboa: Caminho Editorial, 1992.

ROORYCK, J. On two types of underspecification: towards a feature theory shared by syntax and phonology. Probus 6, 1994, p. 207-233.

Recebido em: $14 / 01 / 2013$

Aceito em: 25/02/2013 
